\title{
Silver Nanoparticle Synthesis Using Monosaccharides and Their Growth Inhibitory Activity against Gram-Negative and Positive Bacteria
}

\author{
Colin Pettegrew, Zheng Dong, M. Zubayed Muhi, Scott Pease, \\ M. Abdul Mottaleb, and M. Rafiq Islam
}

Laboratory of Biochemistry, Northwest Missouri State University, Garrett-Strong Science Building 3100, Maryville, MO 64468, USA

Correspondence should be addressed to M. Rafiq Islam; islamr@nwmissouri.edu

Received 12 November 2013; Accepted 2 January 2014; Published 12 February 2014

Academic Editors: L. A. Dykman, A. N. Obraztsov, and T. Pal

Copyright (C) 2014 Colin Pettegrew et al. This is an open access article distributed under the Creative Commons Attribution License, which permits unrestricted use, distribution, and reproduction in any medium, provided the original work is properly cited.

\begin{abstract}
Using various monosaccharides as reductant, we synthesized Ag nanoparticles (NPs) in seconds employing the household microwave method described earlier. The Ag NPs containing colloidal solution showed distinctive colors with varying $\lambda_{\max }$. The sizes of the NPs formed varied significantly from 10 to $35 \mathrm{~nm}$ in good agreement with the localized plasmon resonance ranged from $\sim 300$ to $\sim 600 \mathrm{~nm}$. The antimicrobial properties of these NPs were compared in Gram-negative and positive bacteria in liquid culture. Gram-positive bacteria were highly susceptible compared to Gram-negative microbes-the additional lipopolysaccharide layer covering the peptidoglycan cell wall in the latter somewhat lessens the effect. The results indicated that larger NPs produced by glucose inhibited bacterial growth better than the smallest NPs produced by ribose. This may be attributed to the higher aggregation rate for larger NPs on cell wall. SEM analysis showed accumulation of NPs on cell surface and defect in budding, further supporting the cell wall interaction with Ag NPs. These observations suggested that the growth inhibition of Ag NPs is mediated by interfering with the bacterial cell wall peptidoglycan.
\end{abstract}

\section{Introduction}

The use of nanotechnology in everyday applications continues to increase due to unique chemical, optical, and mechanical properties of nanoparticles (NPs) [1] and it holds promise for multitude of potential applications in the fields of drug delivery [2], catalysis [3], cell and organelle labeling and imaging $[4,5]$, biological sensing [6], and detection of wide range of biomolecules [7-10]. The important characteristic of NPs that separates them from their bulk counterparts is high surface area to volume ratio. Moreover, it has been shown that materials at the nanoscale level have unique chemical and physical properties compared to their bulk counterpart, and these properties are important for a variety of technological applications.

Interaction of NPs with biomolecules and its application in combating microorganisms are a new avenue for research. Increase in bactericide and antibiotic-resistant microbial strains and the toxicity of some of these agents lead to growing interest in new types of safe and cost-effective antimicrobial agents [11]. Recent studies that metal and metal oxide NPs could be used as effective bactericidal materials open the door for development of a new type of antimicrobial materials $[12,13]$. Among the noble-metal NPs, silver received attention due to its interesting physiochemical properties and for the well-known toxicity of its ionic form to bacteria [14]. Silver ions served as bactericide for a while in presulfa-drug era and used in dental resins composites [15] and in coatings of medical devices [16]; however, it was soon abandoned for its toxicity. Sondi and Salopek-Sondi [17] demonstrated Ag NPs as an effective bactericide against Gram-negative bacteria, E. coli. Elechiguerra et al. [18] have reported inhibition of HIV-1 transmission by size dependent interaction of Ag NPs with HIV-1. More antibacterial properties of Ag NPs have also been reported elsewhere $[19,20]$.

For metal nanocrystals, it has been shown that the electromagnetic, optical, and catalytic properties, and biosensor or biological activities are highly influenced by shape and/or 
size of the NPs [21]. This has led to development of a variety of synthetic methods for better control of morphology and size. Silver of NPs of different sizes and shapes has been synthesized by various methods. The most widely used method for the synthesis of Ag NPs is the chemical reduction of silver ions in solution with the use of various reducing agents such as sodium citrate [22], glucose [23, 24], formamide [25], phenylhydrazine [26], and the amino acid tyrosine [27] and cysteine [28]. Often times, the reducing agent is combined with a stabilizing agent to reduce or prevent agglomeration of the NPs synthesized [29]. Other methods described include laser ablation of a silver plate suspended in organic solvents, gamma irradiation of $\mathrm{AgNO}_{3}$ in the presence of polyvinyl pyrrolidone [30], and electroreduction of silver ions in acetonitrile in the presence of tetrabutylammonium salts [31]. Methods involving the use of biological systems, such as fungi [32] and bacterium [33], have also been reported. The ability to control various physical attributes (size and shape) and to include functionalized groups on the surface has made NPs attractive to search for newer applications $[26,34,35]$.

In this study, using common monosaccharides as reductant, we rapidly synthesized Ag NPs of different sizes between 10 and $35 \mathrm{~nm}$ employing the household microwave method described recently [24]. Comparing their antimicrobial potency against Gram-negative and positive bacteria, we found that Ag NPs were more active against Gram-positive bacteria possibly through their interaction with naked peptidoglycans forming the cell wall, while LPS layer in Gramnegative bacteria slowed this interaction. To our knowledge, a comparison of antimicrobial activity of Ag NPs between the two major types of bacteria has not been reported.

\section{Experimental Details}

2.1. NP Synthesis. Silver nanoparticles were synthesized using the household microwave method described previously by Dong et al. [24]. Briefly, aqueous solutions of $0.1 \mathrm{M} \mathrm{AgNO}_{3}$ $(1 \mathrm{~mL})$ and $1.0 \mathrm{M}$ sugar $(1 \mathrm{~mL})$ were mixed together in a medium size glass test tube and vortexed briefly. The tubes were heated for 8-10 seconds in a household microwave oven (J.C. Penney, model 853-5645-00-59, 800 watt) on the highest power setting. To speed up synthesis, up to six test tubes were microwaved at one time in an open plastic test tube holder. Monosaccharide sugars used in the reaction include ribose, fructose, sorbose, glucose, xylose, and galactose. Deionized water was added to the reaction mixtures to maintain a constant reaction volume of $2.0 \mathrm{~mL}$.

2.2. UV-VIS Spectroscopy. Immediately after microwaving, reaction mixtures were analyzed using a Cary 300 Bio UVVIS spectrometer with Varian UV Scan Application, version 3.00 (303), and UV-VIS spectra were obtained between $300 \mathrm{~nm}$ and $800 \mathrm{~nm}$. A $1.0 \mathrm{~mL}$ cuvette with $1 \mathrm{~cm}$ light path was used for all samples. Samples were scanned against a blank prepared of $0.05 \mathrm{M} \mathrm{AgNO}_{3}(1 \mathrm{~mL})$ and $0.50 \mathrm{M}(1 \mathrm{~mL})$ respective sugar just before use.
2.3. Photon Correlation Spectroscopy. The hydrodynamic diameters of the synthesized NPs were determined by photon correlation spectroscopy. The target samples were prepared by diluting $(1: 50)$ the microwaved colloidal mixture directly into nanopure water. Alternatively, the NPs were collected by centrifugation, followed by washing twice with nanopure water. The washed NPs were resuspended in nanopure water and sonicated for $5 \mathrm{~min}$ to disperse aggregated NPs. Measurements were performed using a size analyzer (Brookhaven, model 90 plus). Scattered light was detected at a $90^{\circ}$ angle through a $400 \mu \mathrm{m}$ pin hole at room temperature. The instrument was calibrated using standard reference particles. Following measurements and the values are given as the mean of 5 runs of $60 s \pm$ standard deviation.

2.4. Scanning Electron Microscopy. Silver nanoparticles in bacterial broths were characterized by JOEL field emission scanning electron microscope (FE-SEM) (Model JSM $7600 \mathrm{~F}$ ). The images of the samples were taken setting at the operating conditions of SEM at high voltage from 1.5 to $5 \mathrm{KV}$ with wide distance (WD) from 5.00 to $7.60 \mathrm{~mm}$.

2.5. Antimicrobial Activity. Prior to antimicrobial assay, following microwaving residual silver ions that may adhere to NPs were removed by washing twice with nanopure water, each time the NPs were collected by centrifugation in a microcentrifuge at $5000 \mathrm{~g}$ for $2 \mathrm{~min}$. The washed NPs were dried to constant mass and resuspended in nanopure water and dispersed by brief sonication.

Antimicrobial effects of Ag NPs were performed on Gram-negative, E. coli, and Gram-positive, S. epidermidis, and B. megaterium cells. Overnight cultures diluted in LB to give $1.0 \times 10^{7}$ colony forming unit (CFU) in a total culture volume of $3.5 \mathrm{~mL} \mathrm{LB}$ with or without supplemented with NPs of desired concentration. These culture tubes were incubated in an orbital shaker (GYROMAX 737) at $37^{\circ} \mathrm{C}$ at $225 \mathrm{rpm}$ for indicated period of time. Growth of the bacteria was monitored by measuring absorbance at $600 \mathrm{~nm}$ against LB blank.

\section{Results and Discussion}

3.1. Synthesis and Characterization of Ag NPs. In the present study, commonly available monosaccharides were tested for their ability to synthesize Ag NPs employing the household microwave method we reported previously and to determine any effect on SPR of the NP synthesized. Aqueous solutions containing $\mathrm{AgNO}_{3}$ and monosaccharides were mixed and microwaved for 18-0 seconds in a household microwave, all tubes at once. Monosaccharides are known as reducing sugars because of their ability to reduce $\mathrm{Cu}^{2+}$ in alkaline solution, first described by Fehling, due to the presence of free aldehyde functional group in aldoses or $\alpha$-hydroxymethyl ketone in ketoses. Although the ketone functional group cannot be oxidized per se, it does so by the combination of enediol rearrangements and epimerization. The reaction is carried out in aqueous solution in the absence of any capping agent and required only a couple second of heating 


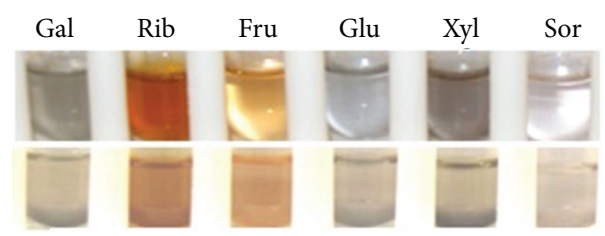

(a)

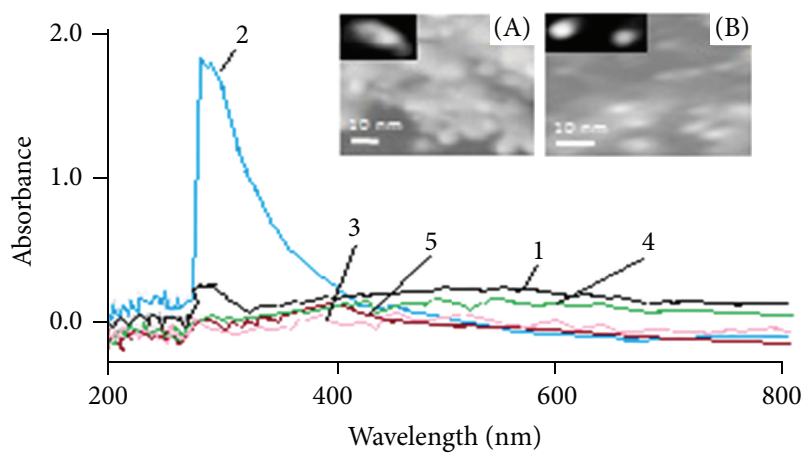

(b)

FIGURE 1: Ag NPs produced are characteristics of monosaccharide. ((a), top panel) Image of colloidal mixtures containing Ag NPs after a solution $\mathrm{AgNO}_{3}(0.05 \mathrm{M})$ and indicated monosaccharide $(0.5 \mathrm{M})$ following $10 \mathrm{~s}$ of microwaving in a household microwave oven. Bright colors were observed for fructose and ribose, dark grey colors for galactose and xylose, and light grey colors for glucose and sorbose. ((a), bottom panel) Image of the tubes in (a) following $20 \mathrm{~h}$ incubation at room temperature in the dark. Ag NPs formed during reaction have settled to the bottom of the tube, allowing for easy collection (arrow). (b) UV-VIS spectra of the colloidal mixtures containing Ag NPs formed in reactions of $\mathrm{AgNO}_{3}(0.05 \mathrm{M})$ and sugar monosaccharides $(0.5 \mathrm{M})$ immediately after microwaving against blanks containing the same concentration of $\mathrm{AgNO}_{3}$ and respective sugar mixed prior to use, but without microwaving: (1) galactose, $534 \mathrm{~nm}$; (2) ribose, $296 \mathrm{~nm}$; (3) fructose, $441 \mathrm{~nm}$; (4) glucose, $559 \mathrm{~nm}$; and (5) xylose, $436 \mathrm{~nm}$. Inset shows SEM images of the Ag NPs collected from the reaction mixtures with glucose (A) and ribose (B), the longest and shortest SPR, respectively.

(8-10 s) in a microwave oven. The initially clear solution in each was turned into dull to bright colors immediately after microwaving. The observed color varied depending on the sugars used in the reaction: bright colors were observed for fructose and ribose; dark grey colors for galactose and xylose; and light grey colors for glucose and sorbose. The colors observed in different reaction mixtures following the reaction are indicative of colloidal solutions of $\mathrm{Ag}^{\circ}$ nanoparticles [36]. The distinctive color formed in the reaction mixtures may also result from the respective oxidized sugars in the solution. However, the metallic silver precipitated out of reaction mixtures after $20 \mathrm{~h}$ of incubation at room temperature exhibited the same color as of the colloidal mixture (Figure 1(a)), suggesting that the colors formed in the reaction mixtures were due to colloidal Ag NPs. However, it may still be possible that the Ag NPs were doped with some oxidized sugars.

Ultraviolet-Visible (UV-Vis) spectroscopy is a valuable tool for structural characterization of metallic NPs. Similar to the metal surface, the electrons in nanoparticles form
TABLE 1: Size of the Ag NPs synthesized using various monosaccharides as reductant. Hydrodynamic diameters were determined by photon correlation spectroscopy and are the means of 5 runs \pm standard deviation. Each run collected over $60 \mathrm{~s}$.

\begin{tabular}{lcc}
\hline Monosaccharide & Type & Size $(\mathrm{nm})$ \\
\hline Ribose (5C) & Aldopentose & $10.3 \pm 0.8$ \\
Xylose (5C) & Aldopentose & $24.8 \pm 1.8$ \\
Galactose (6C) & Aldohexose & $31.0 \pm 3.1$ \\
Glucose (6C) & Aldohexose & $35.2 \pm 3.8$ \\
Fructose (6C) & Ketohexose & $22.7 \pm 4.6$ \\
Sorbose (6C) & Ketohexose & $30.9 \pm 4.9$ \\
\hline
\end{tabular}

a conduction band surrounding the nucleus [37]. The relative excitation of these electrons near the surface of the nanoparticle by wavelength-dependent light results in Surface Plasmon Resonance $[38,39]$. It is well known that the optical properties of NPs depend on size, shape, surface characteristics, and other variables like doping and interaction with surrounding environment and other nanostructures. Red shift occurs with NPs as they aggregate [24]. In addition, the number of SPR peaks decreases as the symmetry of the NPs increases [39]. The UV-Vis absorption spectra taken immediately after microwaving showed a relatively sharp SPR peak at $300 \mathrm{~nm}$ with variable absorbance and all except ribose also showed a 2 nd broader absorption band between $400-550 \mathrm{~nm}$ (Figure 1(b)). The latter may be attributed to the classical SPR of larger silver nanoparticles [36]. The strong SPR absorption peaks below (Figure 1) $430 \mathrm{~nm}$ could be assigned to spherical particles with small diameter due to formation of

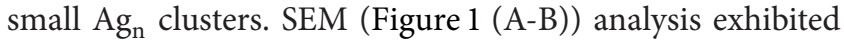
spherical NPs and the sizes of the isolated NPs ranged from $10-15 \mathrm{~nm}$ for ribose to $20-35 \mathrm{~nm}$ for glucose. The sizes of the particles produced with glucose were consistent with the results reported previously [24]. The precise SPR peaks varied greatly and were $296 \mathrm{~nm}$ for ribose, $436 \mathrm{~nm}$ for xylose-both aldopentoses; $534 \mathrm{~nm}$ for galactose, $480 \mathrm{~nm}$ for glucose-both aldohexoses; $441 \mathrm{~nm}$ for fructose and $448 \mathrm{~nm}$ for sorbose-both ketohexoses.

As mentioned above, all except ribose exhibited two SPR peaks. This can be attributed to differences in size rather than shape of the NPs as we have shown previously that the broader peak increases over time with aggregation of NPs [24]. Consistent with this, SEM analysis (Figure 1(b)) revealed that the shapes of NPs produced by both glucose and ribose used as reductant were spherical. Size of the glucose reduced Ag NPs as determined by SEM (Figure 1(A)) was $\sim 35 \mathrm{~nm}$ among the isolated NPs, but significant numbers were aggregated to form larger size. Average sizes of these NPs determined by photon correlation spectroscopy were $35 \mathrm{~nm}$. SEM analysis of the ribose reduced NPs with the shortest SPR showed numerous isolated NPs with size ranged nearly $10 \mathrm{~nm}$, which agreed well with the size determined by photon correlation spectroscopy (Table 1). Sizes of the other monosaccharide reduced NPs ranged from $10 \mathrm{~nm}$ to $35 \mathrm{~nm}$ and correlated well with the SPRs. No correlation was found between either size or shape of the NPs produced with 


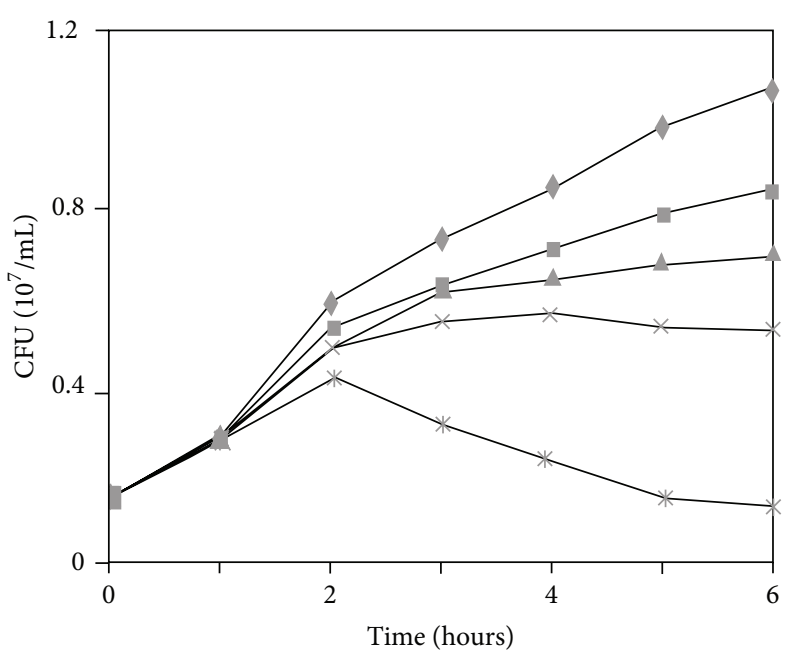

(a)

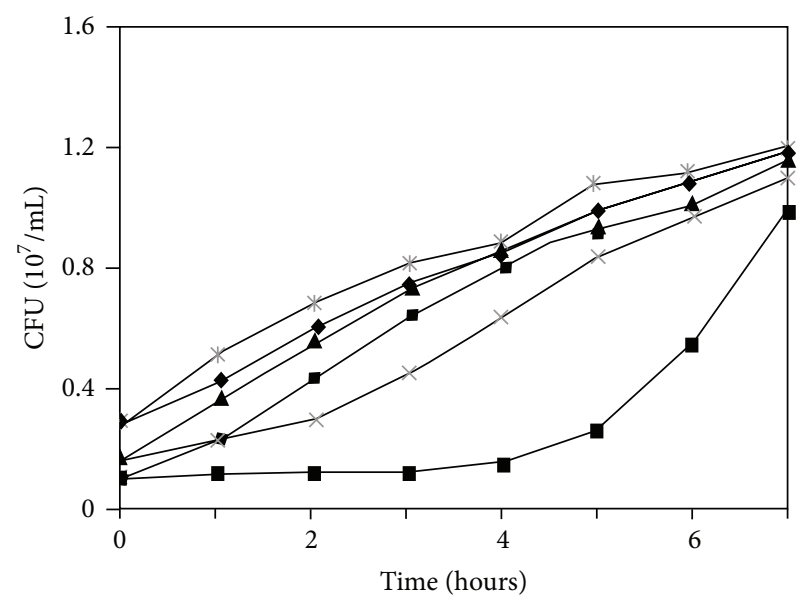

(c)

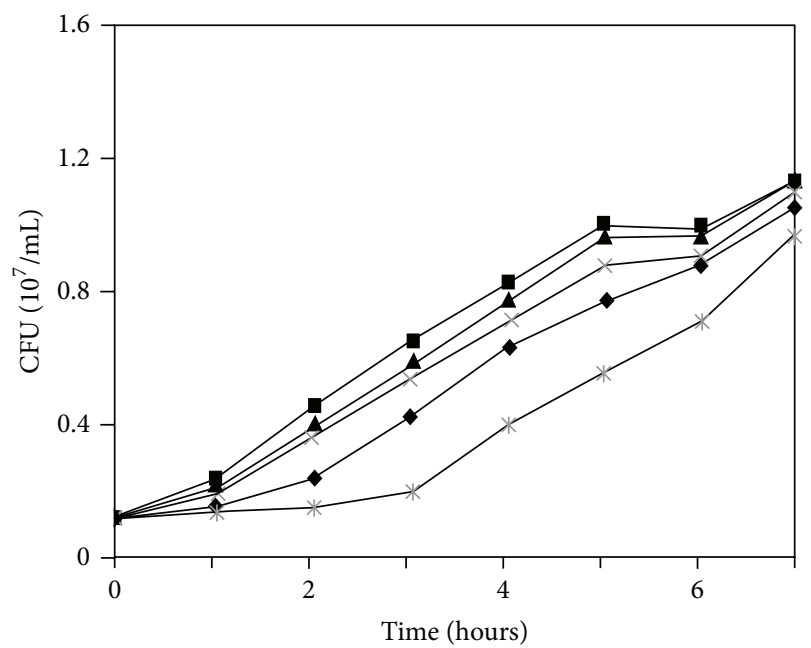

(b)

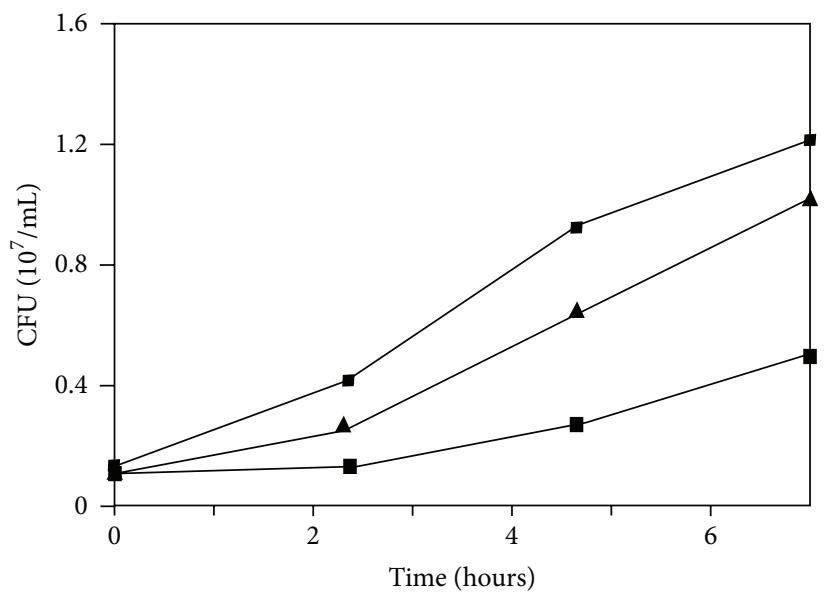

(d)

FIGURE 2: (a) Growth curves of E. coli in LB medium inoculated with $10^{7} \mathrm{CFU}$ of bacteria in presence of different concentrations of Amp: (\$) $0 \mu \mathrm{g} / \mathrm{mL},(\boldsymbol{\square}) 50 \mu \mathrm{g} / \mathrm{mL},(\boldsymbol{\Delta}) 75 \mu \mathrm{g} / \mathrm{mL},(\times) 100 \mu \mathrm{g} / \mathrm{mL}$, and (*) $200 \mu \mathrm{g} / \mathrm{mL}$. (b) Growth curves of E. coli in LB medium inoculated with $10^{7}$ CFU of bacteria in presence of different concentrations of Ag NPs synthesized using glucose: $(\boldsymbol{\square}) 0 \mu \mathrm{g} / \mathrm{mL},(\mathbf{\Lambda}) 5 \mu \mathrm{g} / \mathrm{mL},(\times) 10 \mu \mathrm{g} / \mathrm{mL}$, (\$) $15 \mu \mathrm{g} / \mathrm{mL}$, and (*) $20 \mu \mathrm{g} / \mathrm{mL}$. (c) Growth curves of E. coli in LB medium inoculated with three different populations of bacteria and two different concentrations of silver nanoparticles: (\$) $0 \mu \mathrm{g} / \mathrm{mL} \mathrm{Ag} \mathrm{NPs} \mathrm{at} 0.070 \times 10^{7} / \mathrm{mL} \mathrm{CFU,} \mathrm{( \square )} 20 \mu \mathrm{g} / \mathrm{mL} \mathrm{Ag} \mathrm{NPs} \mathrm{at} 0.070 \times 10^{7} / \mathrm{mL} \mathrm{CFU}$, (ム) $0 \mu \mathrm{g} / \mathrm{mL}$ at $0.130 \times 10^{7} / \mathrm{mL} \mathrm{CFU,} \mathrm{(×)} 20 \mu \mathrm{g} / \mathrm{mL}$ at $0.130 \times 10^{7} / \mathrm{mL} \mathrm{CFU,}(*) 0 \mu \mathrm{g} / \mathrm{mL}$ at $0.262 \times 10^{7} / \mathrm{mL} \mathrm{CFU}$, and $(\bullet) 20 \mu \mathrm{g} / \mathrm{mL}$ at $0.262 \times$ $10^{7} / \mathrm{mL} \mathrm{CFU}$. (d) Growth curves of E. coli in LB inoculated with $10^{7} \mathrm{CFU}$ of bacteria in the presence of silver nanoparticles of different size

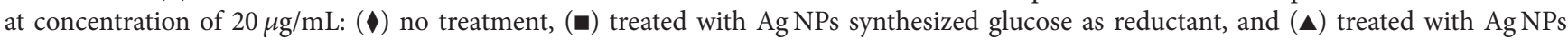
synthesized ribose as reductant.

the functional groups (aldehyde or ketone) present in the monosaccharides nor with the C-length of the sugars.

\subsection{Antimicrobial Effect. Antibacterial tests were performed} against Gram-negative bacteria, E. coli, and Gram-negative bacteria, B. megaterium, and S. epidermis in LB broth supplemented with varying concentrations of Ag NPs. Since $\mathrm{Ag}^{+}$ ions show antimicrobial activity by inactivating proteins and inhibiting replication [40], we removed silver ions as much as possible by washing Ag NPs extensively with nanopure water (see methods) to avoid antimicrobial effect resulting from silver ions. Antibacterial effects were performed initially against Gram-negative E. coli with different concentration of Ag NPs.
Figure 2(b) shows bacterial growth inhibition/delay, which increased with concentration of NPs used. At $50 \mu \mathrm{g} / \mathrm{mL}$ concentration, NPs completely halted growth of E. coli (not shown) over $8 \mathrm{~h}$ growth periods. For comparison, effect of ampicillin on E. coli growth was performed over the same time period (Figure 2(a)). While both showed a concentration dependent effect on E. coli growth, the comparison demonstrated one major difference: Ag NPs affected growth at early hours, which was diminished gradually after peaking around $4 \mathrm{hrs}$, and caught up nearly normal growth after 8 hours. Ampicillin, however, showed a lag period of $\sim 2$ hours, after that growth inhibition was seen increased with time. This difference in growth inhibition pattern may clearly point 


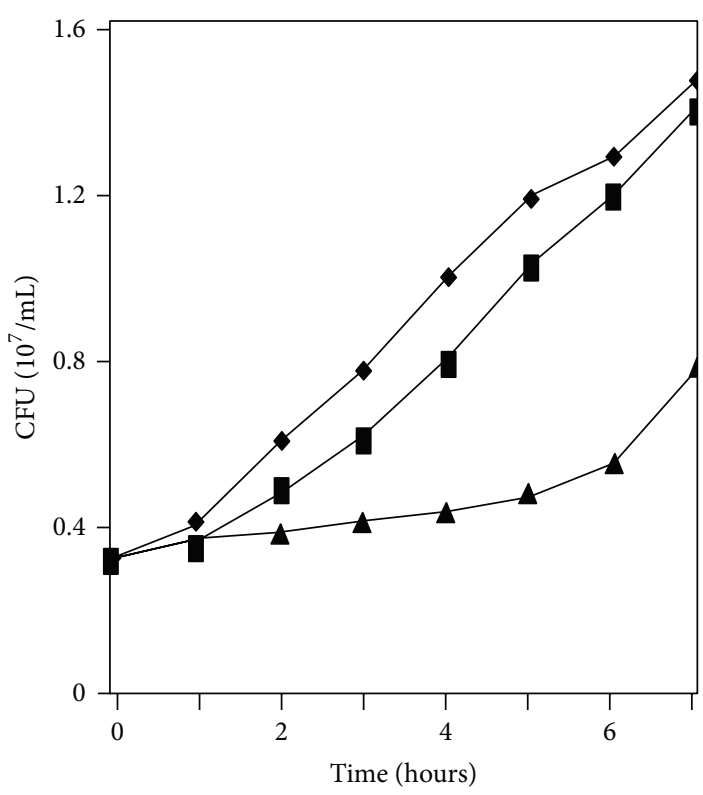

(a)

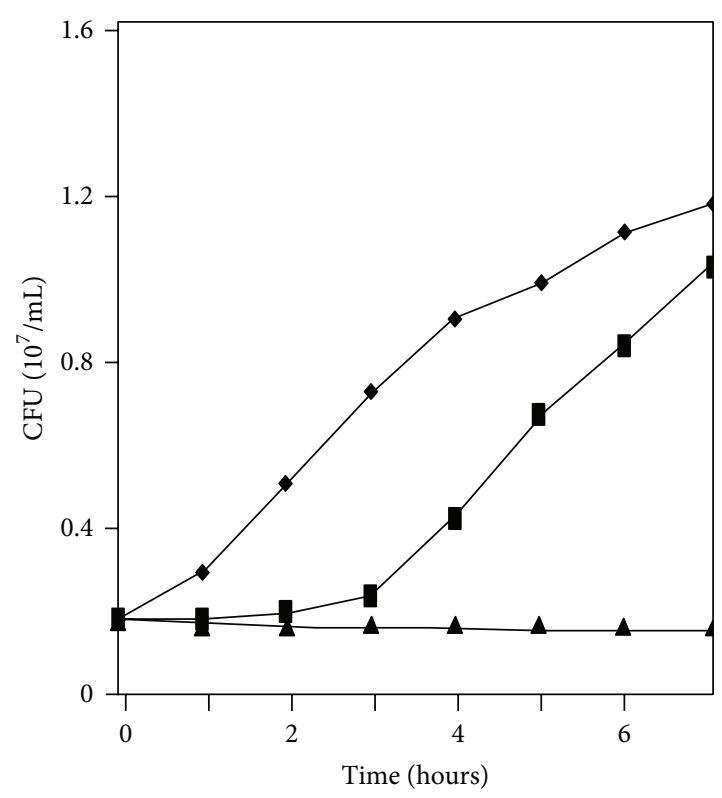

(b)

FIGURE 3: Growth inhibition of Gram-positive microbes by AgNPs synthesized using glucose. (a) Growth curves of S. epidermidis in LB medium inoculated with $10^{7} \mathrm{CFU}$ of bacteria in the presence of different concentration of AgNPs: $(\boldsymbol{\downarrow}) 0 \mu \mathrm{g} / \mathrm{mL},(\boldsymbol{\square}) 10 \mu \mathrm{g} / \mathrm{mL}$, and $(\mathbf{\Lambda})$ $20 \mu \mathrm{g} / \mathrm{mL}$. (b) Growth curves of B. megaterium in LB medium inoculated with $10^{7} \mathrm{CFU}$ of bacteria in the presence of different concentrations of AgNPs: ( $0 \mu \mathrm{g} / \mathrm{mL},(\mathbf{\square}) 10 \mu \mathrm{g} / \mathrm{mL}$, and (४) $20 \mu \mathrm{g} / \mathrm{mL}$.

to the different sites of action. It is well known that ampicillin acts as a competitive inhibitor of the enzyme transpeptidase, which is needed in final stage of bacterial cell wall synthesis in binary fission leading to cell lysis. That is, the site of action for ampicillin is intracellular and requires time for ampicillin to penetrate cell wall and reach the target site. The site of action for Ag NPs is most likely extracellular, the cell wall, which does not require internalization. The reason growth inhibition by Ag NPs was diminished gradually after peaking at $4 \mathrm{~h}$, can be attributed to gradual decrease in the concentration of the NPs, allowing resumption of bacterial cell growth. This gradual decrease process is governed by the interaction of NPs with the intracellular materials (e.g., proteins/peptides) of the destroyed cells, causing their coagulation and removal from the liquid media as suggested earlier [17].

As expected, the extent of growth inhibition depends on the number of cells to begin with: when started with $1 \times$ $10^{6} \mathrm{CFU}$ cells, the growth was drastically delayed up to $8 \mathrm{~h}$ in the presence of $20 \mu \mathrm{g} / \mathrm{mL} \mathrm{NPs}$; on the other hand, it had very little effect when the cells were 3 times more $(3 \times$ $10^{6} \mathrm{CFU}$ ) at the start (Figure 2(c)). These results with E. coli were consistent with those reported by Sondi and SalopekSondi [17], except slight difference in NPs sizes used $(35 \mathrm{~nm}$ versus $50 \mathrm{~nm}$ ).

The Ag NPs produced using ribose have smaller hydrodynamic diameters compared to those synthesized with glucose; thus we examined if the NP size difference has any effect on bacterial growth inhibition. Surprisingly, we found that the larger particle had better effect on the growth delay. Small particles are obviously important if endocytosis into cells [41] is necessary (Figure 2(d)). However, reports from several groups indicated that, in the submicrometer range, larger particles lead to increased efficiencies in transfection [42]. It is speculated that this might be caused, to a large extent, by increased sedimentation of larger complexes, leading to facilitated attachment and interaction to cell wall. Hence, the larger size of Ag NPs formed by glucose might be favorable for growth inhibition over smaller size NPs produced with ribose.

Next, we investigated the effect of Ag NPs on Grampositive bacteria, B. megaterium and S. epidermis. Starting with $3 \times 10^{6} \mathrm{CFU}$ and $20 \mu \mathrm{g} / \mathrm{mL}$ NPs both, Gram-positive bacteria especially $B$. epidermis showed drastic growth inhibition (Figures 3(a)-3(b)), suggesting that Ag NPs are more effective against Gram-positive than Gram-negative microbes. This difference in growth effect can be due to the difference in their cell wall architecture. The outer layer of the Gram-positive bacteria is composed of peptidoglycan, while that layer is covered by a tightly packed lipopolysaccharides layer in Gram-negative cells. It has been reported that Ag NPs directly conjugate with protein molecules and are stabilized by thiol-bearing cysteine residues [18]. While the mechanism of interaction between the NPs and the cell wall components is unfortunately still unresolved, it can be presumed that Ag NPs will interact quickly with naked peptides on the wall of Gram-positive bacteria but slowly with the wall covered by extra layer in Gram-negative bacteria. AgNPs accumulation on the cell membrane and uptake within the cell have also been reported for other bacteria such as $P$. aeruginosa and $S$. typhus [43].

SEM analysis revealed highly reflective metallic on the surface of bacteria compared to untreated cells. It also shows 


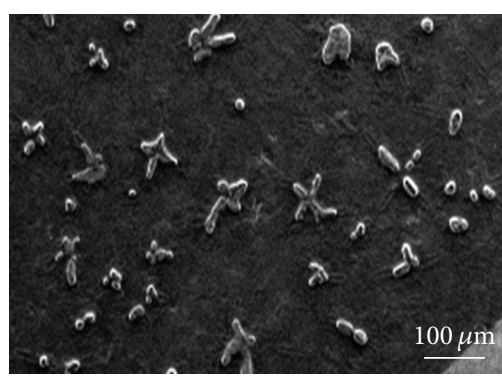

(a)

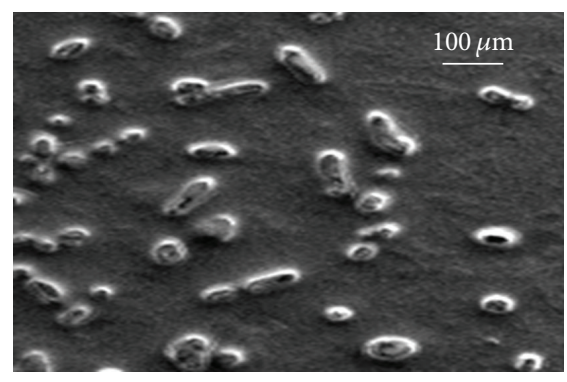

(b)

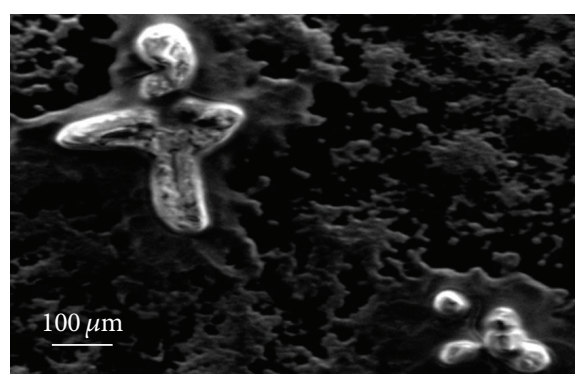

(c)

Figure 4: Scanning electron micrograph of E. coli untreated (a) and treated with $20 \mu \mathrm{g} / \mathrm{mL}$ Ag NPs in liquid medium for $2 \mathrm{~h}$ (b) and enlarged view of the cell showing damage in budding (c).

that the treated cells were significantly changed and the number of budding out cells is drastically reduced, thus preventing their growth (Figure 4). In this study, although the growth inhibition mechanism of the Ag NPs is not fully understood and the mechanisms proposed here are disparate and indirect, they may prove to be synergetic in the action of Ag NPs in bacterial growth inhibition. Further studies are required to fully understand the mechanisms of action. The flexibility of NPs preparation methods, the multitude of functionalization techniques, and facile incorporation of NPs into a variety of media provide incentive for further research and their applications. It should be noted here that a recent report showed that antimicrobial activities of AgNPs were due to aerobic conversion of (PEG and PVP coated) AgNPs to $\mathrm{Ag}^{+}$in aqueous media [44]. However, the released $\mathrm{Ag}^{+}$can also form $\mathrm{Ag}^{\circ}$-containing clusters through chemical reduction with the components in the media and or bacterial cell surface [43]. Whether formation of $\mathrm{Ag}^{+}$is in play in antibacterial activity observed in this study requires further investigation. However, we believe that multiple factors may govern the antibacterial activity.

\section{Conclusion}

Using common monosaccharides as reductant, Ag NPs can be synthesized in seconds employing household microwave. The Ag NPs showed distinctive colors with varying $\lambda_{\max }$ in the range from $\sim 300$ to $\sim 600 \mathrm{~nm}$ and the sizes of the NPs formed varied significantly from 10 to $35 \mathrm{~nm}$ that corresponded well with the SPR bands of Ag NPs produced. The particles were more effective in growth inhibition of Grampositive bacteria most likely mediated by their interaction with naked peptidoglycan of cell wall. The extra LPS layer covering the peptidoglycan seems to lessen the effect in Gram-negative bacteria.

\section{Abbreviations}

NPs: Nanoparticles

SPR: Surface Plasmon Resonance

CFU: Colony forming unit.

\section{Conflict of Interests}

The authors declare that there is no conflict of interests regarding the publication of this paper.

\section{Acknowledgment}

The authors acknowledge the support of CIE facility, Northwest Missouri State University, for SEM and equipment used to perform this study.

\section{References}

[1] S. Link and M. A. El-Sayed, "Spectral properties and relaxation dynamics of surface plasmon electronic oscillations in gold and silver nanodots and nanorods," Journal of Physical Chemistry B, vol. 103, no. 40, pp. 8410-8426, 1999.

[2] P. Ghosh, G. Han, M. De, C. K. Kim, and V. M. Rotello, "Gold nanoparticles in delivery applications," Advanced Drug Delivery Reviews, vol. 60, no. 11, pp. 1307-1315, 2008.

[3] K. Y. Lee, J. Hwang, Y. W. Lee, J. Kim, and S. W. Han, “Onestep synthesis of gold nanoparticles using azacryptand and their applications in SERS and catalysis," Journal of Colloid and Interface Science, vol. 316, no. 2, pp. 476-481, 2007.

[4] P. K. Jain, X. Huang, I. H. El-Sayed, and M. A. El-Sayed, "Noble metals on the nanoscale: optical and photothermal properties and some applications in imaging, sensing, biology, and medicine," Accounts of Chemical Research, vol. 41, no. 12, pp. 1578-1586, 2008.

[5] C. J. Murphy, A. M. Gole, S. E. Hunyadi et al., "Chemical sensing and imaging with metallic nanorods," Chemical Communications, vol. 8, no. 5, pp. 544-557, 2008.

[6] Z. Wang, A. Bonoiu, M. Samoc, Y. Cui, and P. N. Prasad, "Biological pH sensing based on surface enhanced Raman scattering through a 2 -aminothiophenol-silver probe," Biosensors and Bioelectronics, vol. 23, no. 6, pp. 886-891, 2008.

[7] Z. Shu-hong, F. Yong-shan, F. Shuo, and Z. Yun-feng, "Microdetermination of proteins by resonance light scattering technique based on aggregation of ferric nanoparticles," Spectrochimica Acta A, vol. 72, no. 4, pp. 748-752, 2009. 
[8] S. T. Dubas and V. Pimpan, "Green synthesis of silver nanoparticles for ammonia sensing," Talanta, vol. 76, no. 1, pp. 29-33, 2008.

[9] X. Zhao, R. Tapec-Dytioco, and W. Tan, "Ultrasensitive DNA detection using highly fluorescent bioconjugated nanoparticles," Journal of the American Chemical Society, vol. 125, no. 38, pp. 11474-11475, 2003.

[10] Q. Zhang, C. Z. Huang, J. Ling, and Y. F. Li, "Silver nanocubes formed on ATP-mediated nafion film and a visual method for formaldehyde," Journal of Physical Chemistry B, vol. 112, no. 51, pp. 16990-16994, 2008.

[11] M. Rai, A. Yadav, and A. Gade, "Silver nanoparticles as a new generation of antimicrobials," Biotechnology Advances, vol. 27, no. 1, pp. 76-83, 2009.

[12] V. K. Sharma, R. A. Yngard, and Y. Lin, "Silver nanoparticles: green synthesis and their antimicrobial activities," Advances in Colloid and Interface Science, vol. 145, no. 1-2, pp. 83-96, 2009.

[13] P. K. Stoimenov, R. L. Klinger, G. L. Marchin, and K. J. Klabunde, "Metal oxide nanoparticles as bactericidal agents," Langmuir, vol. 18, no. 17, pp. 6679-6686, 2002.

[14] D. B. Hamal and K. J. Klabunde, "Synthesis, characterization, and visible light activity of new nanoparticle photocatalysts based on silver, carbon, and sulfur-doped $\mathrm{TiO}_{2}$, Journal of Colloid and Interface Science, vol. 311, no. 2, pp. 514-522, 2007.

[15] S. W. P. Wijnhoven, W. J. G. M. Peijnenburg, C. A. Herberts et al., "Nano-silver: a review of available data and knowledge gaps in human and environmental risk assessment," Nanotoxicology, vol. 3, no. 2, pp. 109-138, 2009.

[16] L. Loomba and T. Scarabelli, "Metallic nanoparticles and their medicinal potential. Part I: gold and silver colloids," Therapeutic Delivery, vol. 4, pp. 859-873, 2013.

[17] I. Sondi and B. Salopek-Sondi, "Silver nanoparticles as antimicrobial agent: a case study on E. coli as a model for Gramnegative bacteria," Journal of Colloid and Interface Science, vol. 275, no. 1, pp. 177-182, 2004.

[18] J. L. Elechiguerra, J. L. Burt, J. R. Morones et al., "Interaction of silver nanoparticles with HIV-1," Journal of Nanobiotechnology, vol. 3, article 6, pp. 1-10, 2005.

[19] S. Pal, Y. K. Tak, and J. M. Song, "Does the antibacterial activity of silver nanoparticles depend on the shape of the nanoparticle? A study of the gram-negative bacterium Escherichia coli," Applied and Environmental Microbiology, vol. 73, no. 6, pp. 17121720, 2007.

[20] X. Chen and H. J. Schluesener, "Nanosilver: a nanoproduct in medical application," Toxicology Letters, vol. 176, no. 1, pp. 1-12, 2008.

[21] C. Burda, X. Chen, R. Narayanan, and M. A. El-Sayed, "Chemistry and properties of nanocrystals of different shapes," Chemical Reviews, vol. 105, no. 4, pp. 1025-1102, 2005.

[22] P. Raveendran, J. Fu, and S. L. Wallen, "Completely "Green" synthesis and stabilization of metal nanoparticles," Journal of the American Chemical Society, vol. 125, no. 46, pp. 13940-13941, 2003.

[23] X. Gao, G. Gu, Z. Hu, Y. Guo, X. Fu, and J. Song, "A simple method for preparation of silver dendrites," Colloids and Surfaces A, vol. 254, no. 1-3, pp. 57-61, 2005.

[24] Z. Dong, D. Richardson, C. Pelham, and M. R. Islam, "Rapid synthesis of silver nanoparticles using a household microwave and their characterization: a simple experiment for nanoscience laboratory," Chemical Education, vol. 13, pp. 240-243, 2008.
[25] A. Sarkar, S. Kapoor, and T. Mukherjee, "Synthesis of silver nanoprisms in formamide," Journal of Colloid and Interface Science, vol. 287, no. 2, pp. 496-500, 2005.

[26] Y. Li, Y. Wu, and B. S. Ong, "Facile synthesis of silver nanoparticles useful for fabrication of high-conductivity elements for printed electronics," Journal of the American Chemical Society, vol. 127, no. 10, pp. 3266-3267, 2005.

[27] P. R. Selvakannan, A. Swami, D. Srisathiyanarayanan et al., "Synthesis of aqueous Au core-Ag shell nanoparticles using tyrosine as a $\mathrm{pH}$-dependent reducing agent and assembling phase-transferred silver nanoparticles at the air-water interface," Langmuir, vol. 20, no. 18, pp. 7825-7836, 2004.

[28] A. L. Swatek, Z. Dong, J. Shaw, and M. R. Islam, "Self-assembly of silver nanoparticles into dendritic flowers from aqueous solution," Journal of Experimental Nanoscience, vol. 5, no. 1, pp. $10-16,2010$.

[29] J. Ruben Morones and W. Frey, "Environmentally sensitive silver nanoparticles of controlled size synthesized with PNIPAM as a nucleating and capping agent," Langmuir, vol. 23, no. 15, pp. 8180-8186, 2007.

[30] H. S. Shin, H. J. Yang, S. B. Kim, and M. S. Lee, "Mechanism of growth of colloidal silver nanoparticles stabilized by polyvinyl pyrrolidone in $\gamma$-irradiated silver nitrate solution," Journal of Colloid and Interface Science, vol. 274, no. 1, pp. 89-94, 2004.

[31] L. Rodríguez-Sánchez, M. C. Blanco, and M. A. López-Quintela, "Electrochemical synthesis of silver nanoparticles," Journal of Physical Chemistry B, vol. 104, no. 41, pp. 9683-9688, 2000.

[32] K. C. Bhainsa and S. F. D'Souza, "Extracellular biosynthesis of silver nanoparticles using the fungus Aspergillus fumigatus," Colloids and Surfaces B, vol. 47, no. 2, pp. 160-164, 2006.

[33] K. Kalimuthu, R. Suresh Babu, D. Venkataraman, M. Bilal, and S. Gurunathan, "Biosynthesis of silver nanocrystals by Bacillus licheniformis," Colloids and Surfaces B, vol. 65, no. 1, pp. 150-153, 2008.

[34] V. Amendola, S. Polizzi, and M. Meneghetti, "Free silver nanoparticles synthesized by laser ablation in organic solvents and their easy functionalization," Langmuir, vol. 23, no. 12, pp. 6766-6770, 2007.

[35] W.-T. Liu, "Nanoparticles and their biological and environmental applications," Journal of Bioscience and Bioengineering, vol. 102, no. 1, pp. 1-7, 2006.

[36] G. Merga, R. Wilson, G. Lynn, B. H. Milosavljevic, and D. Meisel, "Redox catalysis on "naked" silver nanoparticles," Journal of Physical Chemistry C, vol. 111, no. 33, pp. 12220-12226, 2007.

[37] R. Brause, H. Möltgen, and K. Kleinermanns, "Characterization of laser-ablated and chemically reduced silver colloids in aqueous solution by UV/VIS spectroscopy and STM/SEM microscopy," Applied Physics B, vol. 75, no. 6-7, pp. 711-716, 2002.

[38] M. Kerker, "The optics of colloidal silver: something old and something new," Journal of Colloid And Interface Science, vol. 105, no. 2, pp. 297-314, 1985.

[39] I. O. Sosa, C. Noguez, and R. G. Barrera, "Optical properties of metal nanoparticles with arbitrary shapes," Journal of Physical Chemistry B, vol. 107, no. 26, pp. 6269-6275, 2003.

[40] Q. L. Feng, J. Wu, G. Q. Chen, F. Z. Cui, T. M. Kim, and J. O. Kim, "A mechanistic study of the antibacterial effect of silver ions on Escherichia coli and Staphylococcus aureus," Journal of Biomedical Material Research, vol. 52, pp. 662-668, 2000.

[41] J. F. Hillyer and R. M. Albrecht, "Gastrointestinal persorption and tissue distribution of differently sized colloidal gold 
nanoparticles," Journal of Pharmaceutical Sciences, vol. 90, no. 12, pp. 1927-1936, 2001.

[42] C. Aymonier, U. Schlotterbeck, L. Antonietti et al., "Hybrids of silver nanoparticles with amphiphilic hyperbranched macromolecules exhibiting antimicrobial properties," Chemical Communications, vol. 8, no. 24, pp. 3018-3019, 2002.

[43] J. R. Morones, J. L. Elechiguerra, A. Camacho et al., "The bactericidal effect of silver nanoparticles," Nanotechnology, vol. 16, no. 10, pp. 2346-2353, 2005.

[44] Z. Xiu, Q. Zhang, H. L. Puppala, V. L. Colvin, and P. J. J. Alvarez, "Negligible particle-specific antibacterial activity of silver nanoparticles," Nano Letters, vol. 12, pp. 4271-4275, 2012. 

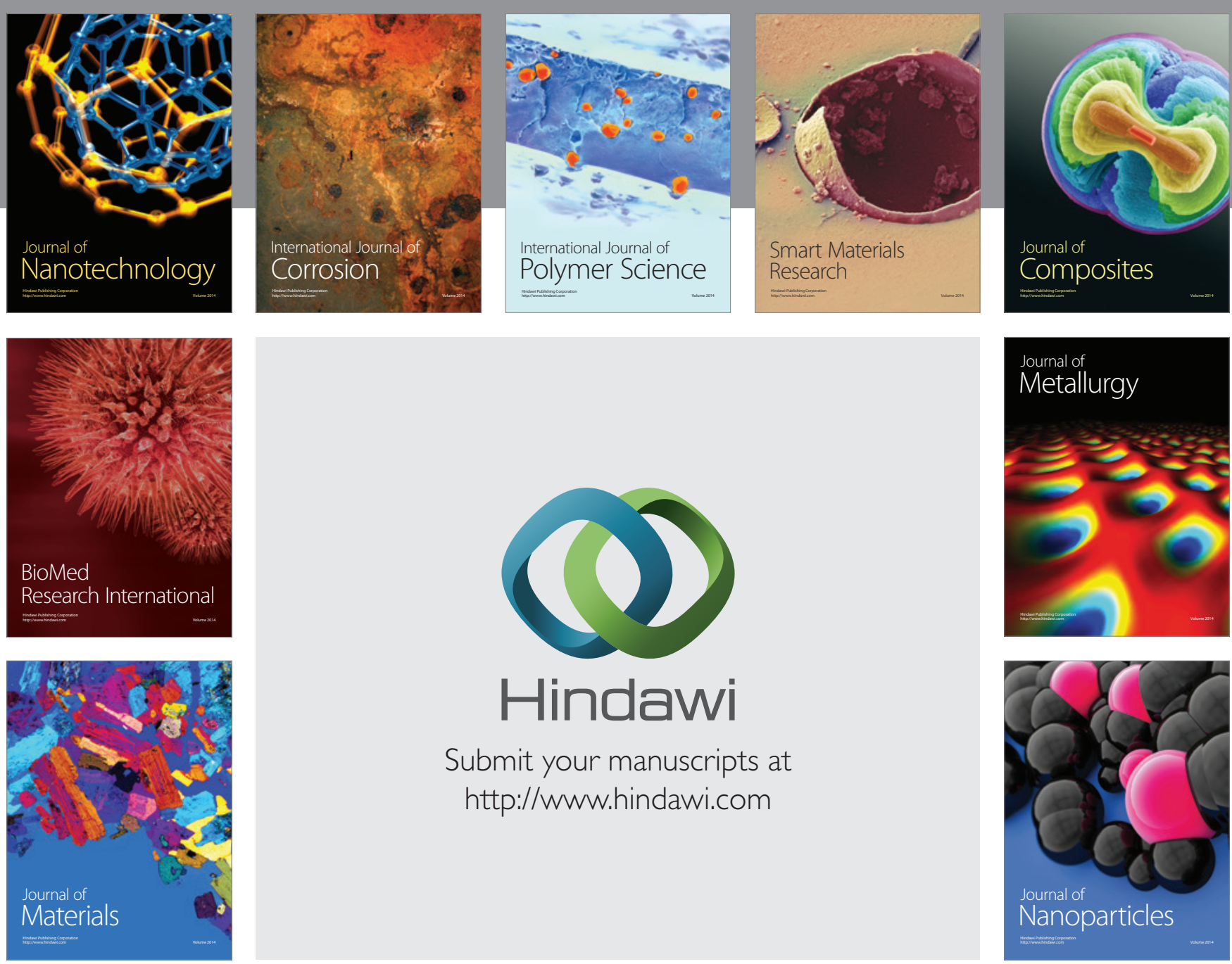

Submit your manuscripts at http://www.hindawi.com
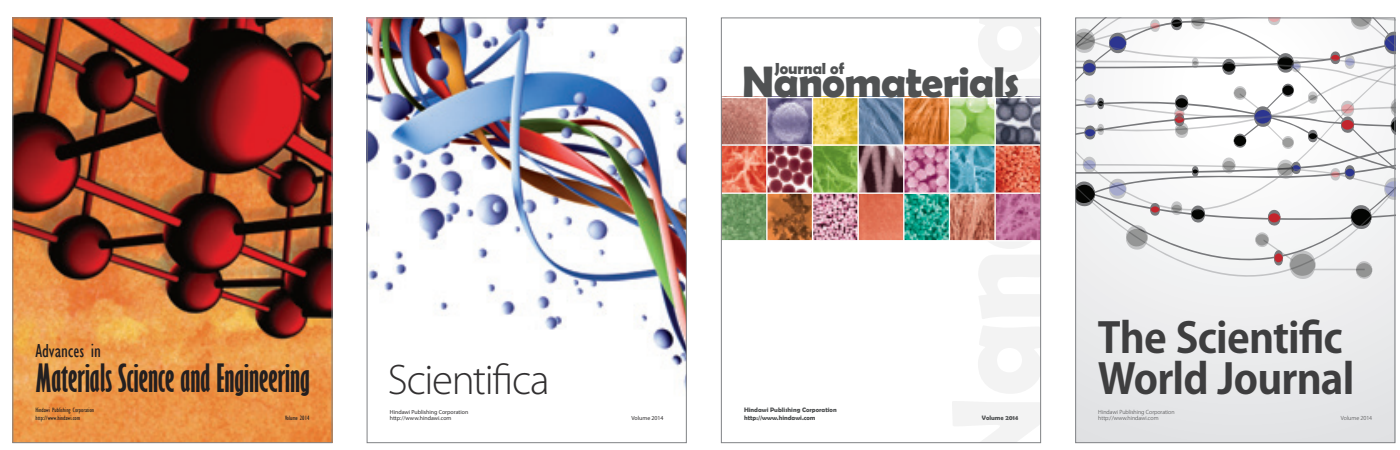

\section{The Scientific World Journal}
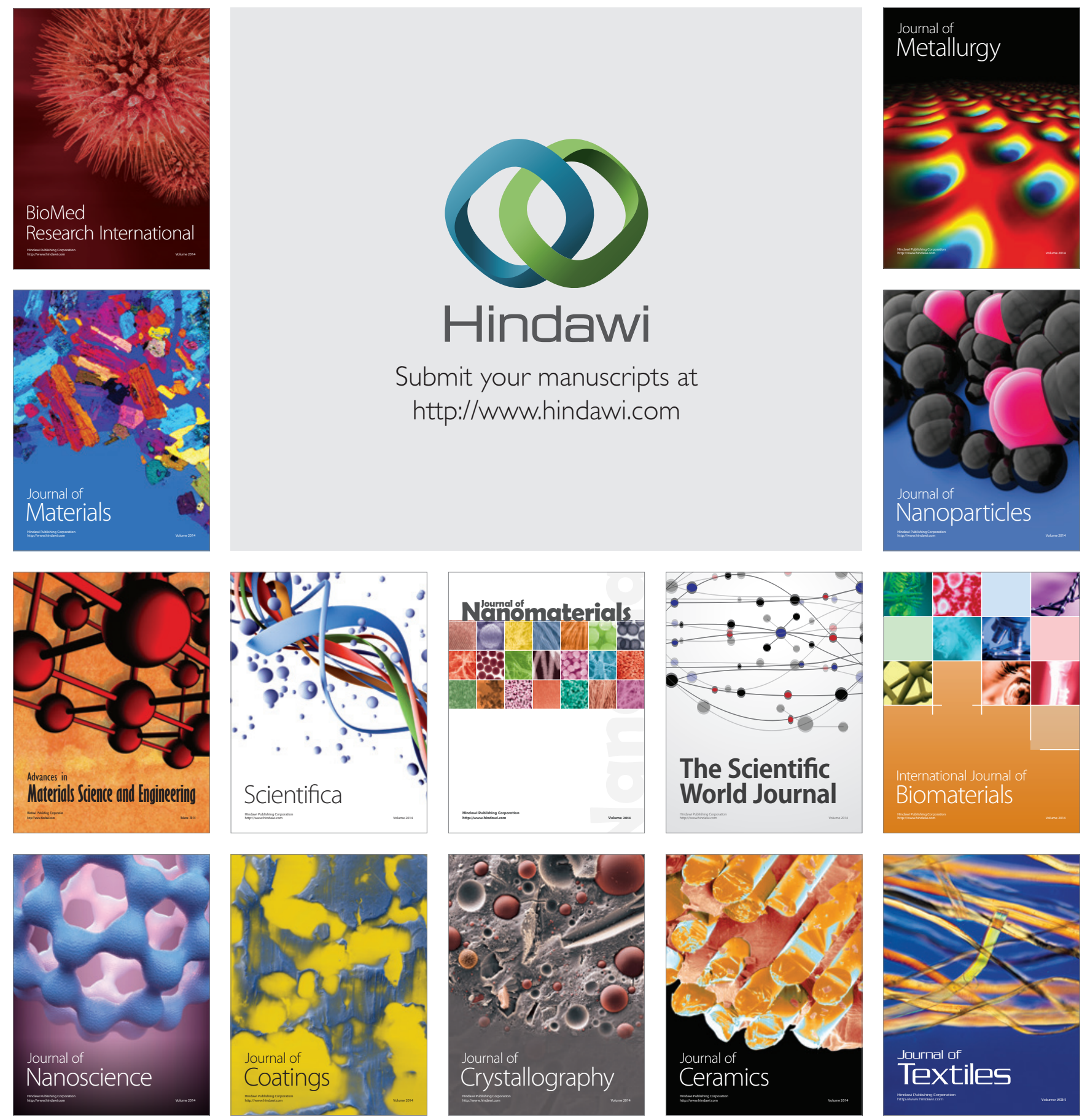